$\mathbf{R}_{\text {ESEARCh }} \mathbf{P}_{\text {APER }} \longrightarrow$ FOOD SCIENCE

e ISSN-2230-9403 — Visit us :

www.researchjournal.co.in

Volume 9 | Issue 1 | April, 2018 |7-11

DOI : 10.15740/HAS/FSRJ/9.1/7-11

\title{
Food intake and food adequacy of rural school children in the age group of 7-9 years
}

\author{
Mahima Kumari and Saroj Dahiya
}

\begin{abstract}
A present study was carried out to assess the information regarding food intake and food adequacy of the school children (7-9 year) of the two villages viz., Alakhpura and Barsi in Bawani Khera blocks of Bhiwani district. A sample of 100 school children was randomly selected. Data on dietary intake was collected by 24 hour recall method and analysed for food intake which was calculated and compared with recommended dietary intake. It was observed that food stuff like pulses, milk and milk products, roots and tubers, green leafy vegetables, other vegetables, fruits, sugar and jaggery, and fats and oils were lower than RDI in respondent of both the villages. Adequacy of food intake revealed that the intake of roots and tubers, green leafy vegetables, other vegetables and fruits milk were inadequate (50\% of RDI) among majority of school going children. The intake of pulses and fats and oils were marginally inadequate and milk and milk products were marginally adequate. On the other hand, most of the children were taking cereals and sugars adequately.
\end{abstract}

Key Words : School children, Food intake, Adequacy, Recommended dietary intake

How to cite this article : Kumari, Mahima and Dahiya, Saroj (2018). Food intake and food adequacy of rural school children in the age group of 7-9 years. Food Sci. Res. J., 9(1): 7-11, DOI : 10.15740/HAS/FSRJ/9.1/7-11. 